\title{
Centennial climate changes and their global associations in the Yangtze River (Chang Jiang) Delta, China and subtropical Asia
}

\author{
William Y. B. Chang ${ }^{1,2,3}$, George King ${ }^{4}$ \\ ${ }^{1}$ Center for Great Lakes \& Aquatic Sciences, The University of Michigan, Ann Arbor, Michigan 48109, USA \\ ${ }^{2}$ EPA Environmental Research Laboratory, Corvallis, Oregon, USA \\ ${ }^{3}$ Division of International Programs, National Science Foundation, Arlington, Virginia, USA \\ ${ }^{4}$ Mantech Environmental Technology, Inc., EPA Environmental Research Laboratory, Corvallis, Oregon, USA
}

\begin{abstract}
Examination of the climate of China's Yangtze River (Chang Jiang) Delta over the past $100 \mathrm{yr}$ suggests that the major interannual climate fluctuations in the region are closely related to global climate variability and can be attributed to atmosphere-ocean interactions. Significant climate cycles of 2-3,5-6 and 38 yr during the last 100 yr were identified using digital weather records for the Yangtze River Delta. The $2-3$ yr cycle was identified as part of the Quasi-Biennial Oscillation (QBO) related to the East Asia Circulation Index, while the 5-6 yr cycle is generally associated with El Nino/Southern Oscillation (ENSO) activities. Five significant flood years and 6 significant drought years were identified during the last 100 yr period. Large interannual rainfall variability in the Delta following the ENSO was found to be a part of world-wide climate variations occurring in the oceanatmosphere system associated with ENSO. Heavy precipitation and an extended Mei-Yu period, which characterize each of these extreme flood events in the Delta, are correlated with elevated sea surface temperatures in the Equatorial Eastern Pacific and over the Kuroshio Current. The intervals between the major flood events can be derived from a combination of the $2-3$ and 5-6 yr cycle periods. This suggests that the major flood events in the region appear to be influenced strongly by both ENSO activities and the QBO.
\end{abstract}

KEY WORDS: El Nin̄o/Southern Oscillation (ENSO) - Yangtze River · Floods · Quasi-Biennial Oscillation $(\mathrm{QBO})$

\section{INTRODUCTION}

Climate is the most important environmental factor influencing natural and man-made systems. Changes in the extremes, variability, and mean conditions of climate can have remarkable effects on the physical, chemical, biological, economic, and social environments on earth. Cycles of changes in the extremes, variability, and mean conditions of climate have ranged from less than decades to more than a millennium and are correlated to global hemispheric circulation. While long-term changes in climate $(>1000 \mathrm{yr}$ ) are important for understanding the earth's physical environments, climatic variability in centennial or decadal periods is critical to man-made systems and institutions, and can extensively affect human well-being.
Analysis of the climate of the East Asia Pacific region has been limited, and much of the available information is published only locally. Understanding climate patterns in the East Asia Pacific and their role in global climate is important, since this region is a key part of global climate and can provide information important to the forecasting of global weather events. Furthermore, since this region has a high population density, the effects of climate variability have had a remarkable impact on man-made systems and institutions here. Understanding climate variability and patterns is, therefore, critical for mitigating the impact of extreme climate events and may greatiy reduce damage to natural and man-made systems.

Examining $100 \mathrm{yr}$ climate records from China's Yangtze River (Chang Jiang) Delta enables us to im- 
prove our understanding of extreme weather events, patterns of interannual climate variability and the potential impact of extreme weather events on human systems, as well as the association of these events with Asian monsoon activities and ocean-atmospheric interaction. In this study, the temperature and precipitation data from this database are analyzed to provide information on the climate periods, trends, and patterns over the last $100 \mathrm{yr}$ and to show the interaction between the climate in the Delta and the Asian monsoon. The occurrence of extreme climate events (i.e. floods and droughts) during the last $100 \mathrm{yr}$ is reported, the relationships between these extreme climate events and the El Niño/Southern Oscillation and Quasi-Biennial Oscillation are explored, and the impacts on natural and man-made system are discussed.

\section{CLIMATE OF CHINA AND THE RIVER DELTA}

The Pacific Ocean and the Tibetan Plateau are the 2 most important physical geographic features here, giving rise to a unique set of climate conditions in eastern Asia. This includes pronounced summer and winter monsoon activities, a strong continental climate and distinct regional weather types. These unique climate conditions shape the environments in eastern Asia, where $95 \%$ of the total cultivated land and $95 \%$ of the renewable resources in China, such as agricultural production, animal husbandry and fisheries, are influenced by the monsoon (Zhu et al. 1990).

China spans 4 major climate zones: the cold-temperate, temperate, subtropical, and tropical. Seasonal monsoons play a major role in the climate of this part of Asia providing the majority of annual precipitation and affecting the onset of the 'Mei-Yu' ('plum rain', occurring during the plum flower blossom season) period, precipitation amount, temperature, and the occurrence of droughts and floods. The summer monsoon activity normally begins in April, peaks in June, July, August and September, and diminishes after October. The annual precipitation amount in China decreases from the southeast to the northwest and from coastal areas to inland regions, varying from $1500-2000 \mathrm{~mm} \mathrm{yr}^{-1}$ in southeastern China, to $1250 \mathrm{~mm}$ in the middle and lower reaches of the Yangtze River (Chang Jiang) Valley, to $750-1000 \mathrm{~mm}$ in the Yellow River (Huang He) Valley.

The Yangtze River Delta is located at the mouth of the Yangtze River in the easternmost part of China. The Delta is bordered by the Yangtze River on the north and the Quiantang River on the south (Fig. 1). It has a transitional climate, being situated between the humid subtropics of southern China to the south and the dry Yellow River Valley to the north. Average annual temperature and precipitation in the Delta show a pattern similar to the overall pattern in China, decreasing from the coastal to inland areas and from the southeastern to the northwestern areas of the Delta. The cumulative degree-days (above $10^{\circ} \mathrm{C}$ ) value for the Delta is between 5000 and 5300, decreasing from the southwestern to the northeastern portions of the Delta, with an average annual temperature of $15^{\circ} \mathrm{C}$. The same pattern holds for total annual precipitation in the Delta; it decreases from $1500 \mathrm{~mm}$ in the southeastern portion to $1000 \mathrm{~mm}$ in the northwestern areas, with an average precipitation of $1450 \mathrm{~mm}$ in Hongzhou, $1140 \mathrm{~mm}$ in Shanghai and $1000 \mathrm{~mm}$ in Nanjing.

Variability in the intensity and duration of the monsoon activity can strongly affect the amount of precipitation and regional temperature in this delta. For example, interannual variability of more than $1200 \mathrm{~mm}$ (about a 1 -fold change) in precipitation has been recorded in the Yangtze River Delta (Zhu et al. 1990).

Fig. 1. Lake Tai and the Yangtze River Delta, China 
Table 1 Weather records used in this study. The temperature and precipitation data were provided by the Chinese Academy of Meteorological Sciences

\begin{tabular}{|ccccc|}
\hline City & Latitude & Longitude & Elevation (m) & Data period \\
\hline $\begin{array}{c}\text { Hongzhou } \\
\text { Precipitation } \\
\quad \text { Temperature }\end{array}$ & $30^{\circ} 16^{\prime} \mathrm{N}$ & $120^{\circ} 10^{\prime} \mathrm{E}$ & 10 & $1905-1989$ (missing 1938-1940, 1943-1945) \\
$\begin{array}{c}\text { Nanjing } \\
\text { Precipitation } \\
\quad \text { Temperature }\end{array}$ & $32^{\circ} 13^{\prime} \mathrm{N}$ & $118^{\circ} 4^{\prime} 7^{\prime} \mathrm{E}$ & 67.9 & $1907-1989$ (missing 1938-1941, 1943-1949) \\
$\begin{array}{c}\text { Shanghai } \\
\text { Precipitation } \\
\text { Temperature }\end{array}$ & $31^{\circ} 12^{\prime} \mathrm{N}$ & $121^{\circ} 26^{\prime} \mathrm{E}$ & 7 & $1905-1987$ (missing 1938-1940, 1945) \\
\hline
\end{tabular}

\section{METHODS}

Data sources. Long-term continuous weather records (monthly temperature and precipitation) from Shanghai, Nanjing, and Hongzhou were obtained from the Chinese Academy of Meteorological Sciences. These records cover the period from the first decade of this century to the present, except for the data from Shanghai which date from before 1890 (see Table 1). These are the longest continuous instrumental records available in subtropical China, where most records are available only from the 1950 s to the present. The 3 sites selected form the vertices of the Delta (Fig. 1), and represent the 3 extremes of weather types in this Delta. Gaps in the data correspond to war periods in China. In order to provide estimates for periods of missing data, the Quasi-Newton method, as modified by Fletcher \& Powell (SYSTAT 1972), was used. The method includes 2 repeated steps: (1) a time series model is estimated using available data, then the missing values are estimated using the model established; (2) the model estimation is repeated using the estimated values for missing data until the summed residues between the model prediction and the data reach asymptotic levels. The data including the estimated missing values were analyzed using periodogram analyses of Fourier transformations.

Data analyses. Several analytical methods were used to study the patterns, trends, and cycles of the $100 \mathrm{yr}$ climate records from the Yangtze River Delta. These included periodogram analysis, moving averages and analysis of extreme climate events. Extreme climate events were selected using the precipitation data. The selection criteria for extreme precipitation events are those published by the Chinese Academy of Meteorological Science, which defines flood and drought years as those years with annual precipitation $15 \%$ above and below the average annual precipitation, respectively (Chen 1986). Years with major annual floods and droughts are defined as those in which precipitation is
$40 \%$ above or below average, respectively. The average annual precipitation for each city was calculated using all weather records (with no replacement of missing values) available for the site. Regional drought or flood years were defined as those years when such events occurred in all 3 cities (see Table 2).

The temperature and precipitation cycles of this region were determined using the moving average method and periodogram analysis (Wei 1990). Moving averages were applied to the data to reduce the variability prior to periodogram analysis. The periodicities were derived from periodogram analysis of the Fourier transformation using the model given by Wei (1990), as shown in Eq. (1)

$$
Z_{t}=\sum_{k=0}^{n / 2}\left(a_{k} \cos \omega_{k} t+b_{k} \sin \omega_{k} t\right)+e_{t}
$$

where $Z_{t}$ is the Fourier function with $n$ observations; $a_{k}$ and $b_{k}$ are Fourier coefficients; $\omega_{t}=2 \pi k / n, k=0,1, \ldots$, $(n-1) / 2$, the Fourier frequency; $e_{t}$ is a Gaussian white noise series of $N\left(0, \sigma^{2}\right)$. Periodicities or cycles were determined as $P=2 \pi / \omega$. The significant cycles were identified using both Fisher's exact statistics ( $T$, Fisher's exact test for the maximum periodogram) and the $F$-test (with 2 and $n-3$ degrees of freedom).

\section{RESULTS AND DISCUSSION}

During the last $100 \mathrm{yr}$, there have been 5 regional flood years and 6 drought years in the Yangtze River Delta, as shown in Table 2. We found that in all regional flood years, flood-level precipitation occurred 6 or 7 mo after the beginning of the El Niño-Southern Oscillation (ENSO), which generally occurs during the Christmas period, in late December/early January. An El Niño type event is characterized by the appearance of anomalously warm sea surface temperatures and abnormally heavy rainfall in the equatorial Pacific, and an invasion of anomalously warm surface 
Table 2. Years of floods and droughts occurring in the Yangtze River Delta. The list of ENSO episodes included in this table is from Rasmusson \& Carpenter (1983)

\begin{tabular}{ccc}
\hline Flood years & ENSO & Drought years \\
\hline 1905 & 1905 & 1929 \\
1915 & 1914 & 1934 \\
1931 & 1930 & $1967^{\mathrm{a}}$ \\
1954 & 1953 & 1968 \\
$1983^{\mathrm{a}}$ & 1982 & 1978 \\
& & $1979^{\circ}$
\end{tabular}

${ }^{2}$ Only 2 of the 3 cities meet the rainfall criteria

water off the coast of Peru and southern Ecuador (Quinn et al. 1987). The Southern Oscillation is loosely defined (Berlage 1966) as a fluctuation in the intensity of the intertropical general atmospheric and hydrospheric circulation over the Indo-Pacific region. It is generally believed that the El Niño occurs as part of an extreme instance of the Southern Oscillation (Hayden 1993). El Niño/Southern Oscillation is a term

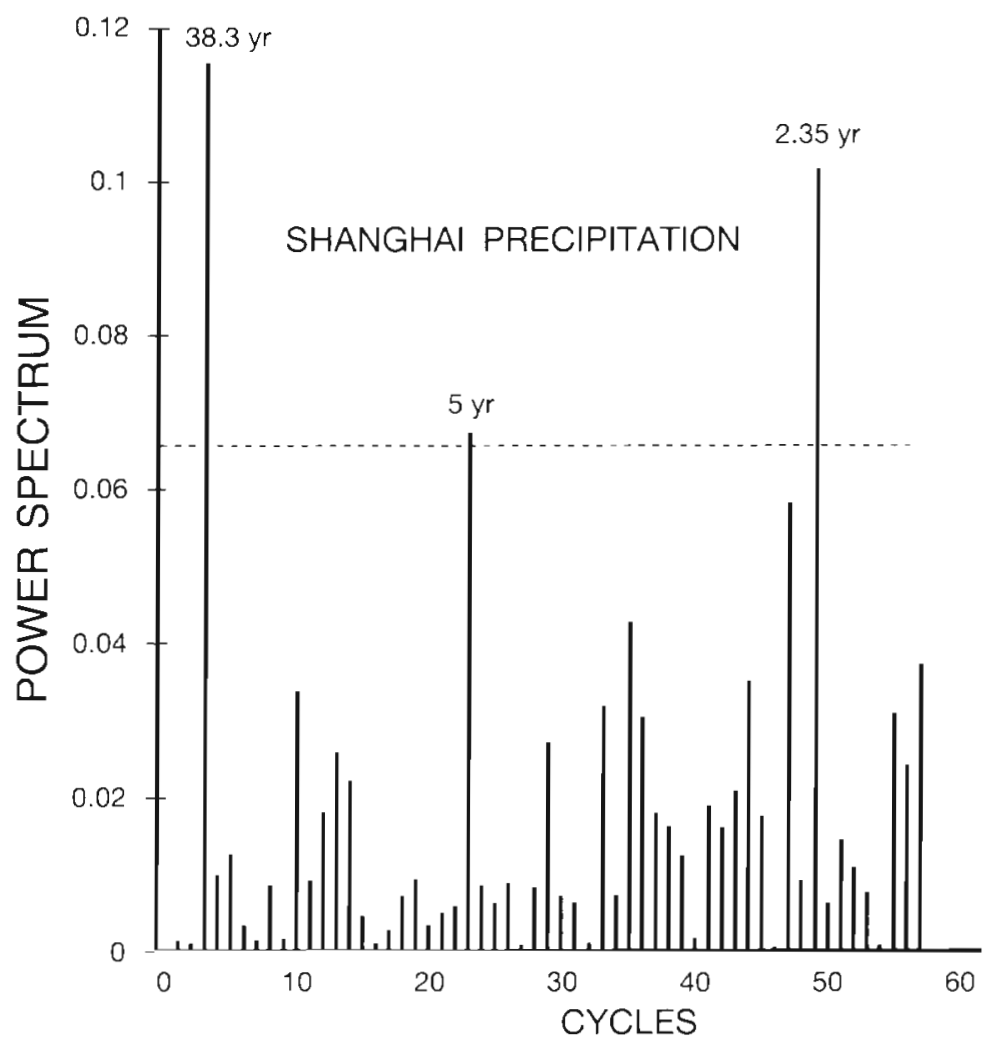

Fig. 2. Periodogram of annual precipitation at Shanghai. Shown are power spectra for Shanghai using data from 1873 to 1987 . Abscissa is frequency in cycles per $100 \mathrm{yr}$ (number above peaks indicate cycle, in years). Ordinate indicates relative power. Horizontal dashed line is $T$, with a significance level of 0.05 . The significant $(p<0.05)$ precipitation periods identified are $2-3,5-6$ and $38 \mathrm{yr}$. The $2-3$ and $5-6$ yr periods are observed at all 3 recording sites in the Delta used to describe that an El Niño event initially found during the Christmas period coincides with falling pressure in the Pacific (Tahiti) (Quinn et al. 1987. Rasmusson \& Arkin 1987, Redmond \& Koch 1991, Hayden 1993).

The heavy precipitation during the extreme flood events was accompanied in the Yangtze River Delta by an extended Mei-Yu period, which was found to arrive 2 to $3 \mathrm{wk}$ earlier and to depart 2 to $3 \mathrm{wk}$ later than an average one. The years with strong regional droughts in the Delta, however, were not found to correlate with ENSO activities (Table 2). This report provides the first indication of the association between regional flood events in the Yangtze River Delta and ENSO events. Previous research has shown that droughts can occur in northern and southern China during the occurrence of ENSO (Diaz \& Fu 1987). However climate dynamics operating between ENSO and the flood and drought events are complicated. The results shown here represent one of the possible responses to ENSO events. In other parts of the Yangtze River Valley, droughts have been reported to follow ENSO activities.

The relationships between temperature and precipitation were examined for the years when floods and droughts occurred. No discernible patterns in these relationships were noted during flood periods, but the summer temperatures during drought years were, on average, $1^{\circ} \mathrm{C}$ higher than during an average year. The higher than normal summer temperature during the drought years could have been caused by lower cloud cover, or by more of the incoming solar radiation being converted to sensible heat as opposed to the latent heat of evaporation.

Several significant $(\mathrm{p}<0.05)$ climate $\mathrm{cy}$ cles were identified in the last 100 yr for the Yangtze River Delta using periodogram analysis. The precipitation cycles were $2-3$, $5-6$, and 38 yr long (Figs. 2 \& 3). Series simiilar to these have been found for the Yangtze River Valley and southern China using the proxy records of droughts and floods between 1470 and 1979 AD (Wang \& Zhao 1981). The 2-3 yr rainfall cycle is a phenomenon called the Quasi-Biennial Oscillation (QBO). Wang \& Zhao (1981) reported that the QBO was strongly correlated with the East Asia Circulation Index (EAI), which they defined as the sum of pressure at the intersections $50^{\circ} \mathrm{N}, 130^{\circ} \mathrm{E}$ and $50^{\circ} \mathrm{N}, 140^{\circ} \mathrm{E}$. A high EAI correlates with floods in the Yangtze River area and droughts in northern and southern China, 


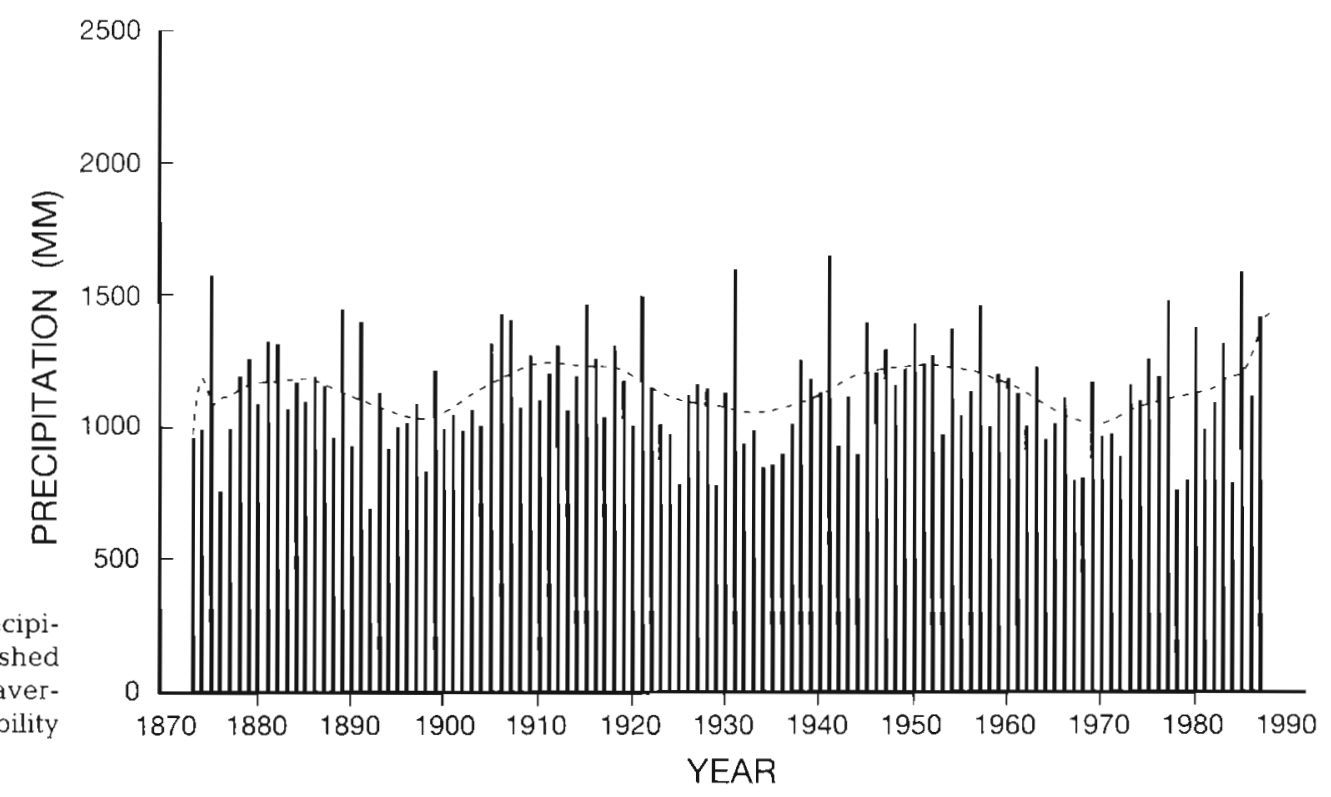

while a low EAI corresponds to a reversal of these climate conditions. Wang \& Zhao (1981) also indicated that the areas of sea-level pressure in the Pacific correlate significantly with the $2-3$ yr rainfall cycle (QBO), which contributes to the occurrence of droughts and floods in Shanghai. Chen et al. (1991), using global monthly zonal wind data from the period between 1968 and 1985, found a 3.5 yr cycle that was significantly related to ENSO. However, the precipitation data we analyzed for the Yangtze River Delta failed to show that the 3.5 yr oscillation was statistically significant.

Wang \& Zhao (1981) showed that the 38 yr cycle is significantly $(p<0.05)$ correlated to the Southern Oscillation Index (SOI), which is defined as the pressure difference between intersections $10^{\circ} \mathrm{N}, 160^{\circ} \mathrm{W}$, and $10^{\circ} \mathrm{S}, 140^{\circ} \mathrm{E}$, and is linked with the intensity of the Western Pacific Subtropical High. However, Quinn et al. (1987) indicated that a cycle of 33 to 37 yr has been found in many meteorological phenomena, including tree rings and long rainfall records, and may be caused by the interference of cycles of different lengths as a result of statistical smoothing. This cycle, first reported by Sir Francis Bacon in 1625 and rediscovered in 1890 by E. Bruckner, and therefore generally referred to as the Bruckner cycle, has been criticized as having little basis in reality (Fairbridge 1987, Quinn et al. 1987).

The temperature trends for Shanghai, Nanjing and Hongzhou over the last 100 yr (Fig. 4a) exhibit a pattern similar to that of the northern hemisphere as a whole (Lough et al. 1987). Average annual temperatures increased at the beginning of this century, reaching a high in the 1940s. Major fluctuations can be observed after the 1940s, with a general increase in temperature since the 1970 s. Because these records were collected from the urban areas, the 'urban warming' effect from human energy consumption may have had a significant effect on the recorded temperatures. Zhao (unpubl.) indicated that a $0.2^{\circ} \mathrm{C}$ increase may be attributed to urban warming for a city with a population greater than 1 million. The cumulative degreedays value (base $10^{\circ} \mathrm{C}$ ) exhibited trends similar to that of the temperature changes, showing a major increase from 1900 to the 1940 s from a level of 4800 to 5100 Celsius degree-days (Fig. 4b). The significant $(p<0.05)$ temperature periods identified for the Delta area were $5-6$ and 38 yr

\section{Hemispheric associations}

Mei-Yu Front

The Mei-Yu Front, a part of the East Asia Monsoon, is closely linked to northern hemispheric circulation and is shaped by the ocean-atmosphere interaction in the Pacific, and the large Asian landmass and Tibetan Plateau. In winter, the westerlies of central Asia move southward. The Tibetan Plateau and surrounding landmass serve as a heat sink while the Pacific Ocean is the heat source, and the prevailing wind is northeasterly. In summer, the westerlies move north of the Tibetan Plateau. The large landmass serves as a heat source with the ocean as a heat sink, and a southwesterly wind predominates. The warm air moves northward, accompanied by heavy rain, covering all of eastern Asia and at times extending to central Asia.

The Mei-Yu Front is a part of this warm air movement with high moisture, and is a major physical phenomenon predominating during early summer in the 


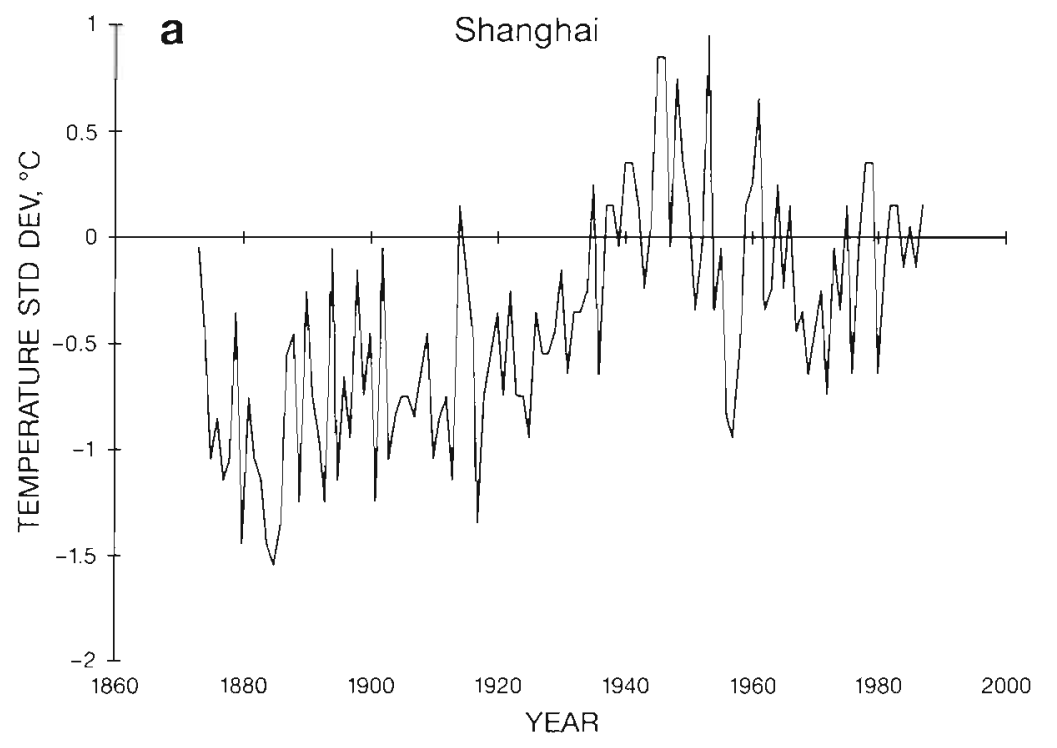

Fig. 4. (a) Annual temperature at Shanghai, expressed as standard deviation of the mean, where the mean is the average value of annual temperature beween 1946 and 1960; (b) cumulative degree-days (base $10^{\circ} \mathrm{C}$ ) at Shanghai using the averaged monthly temperature

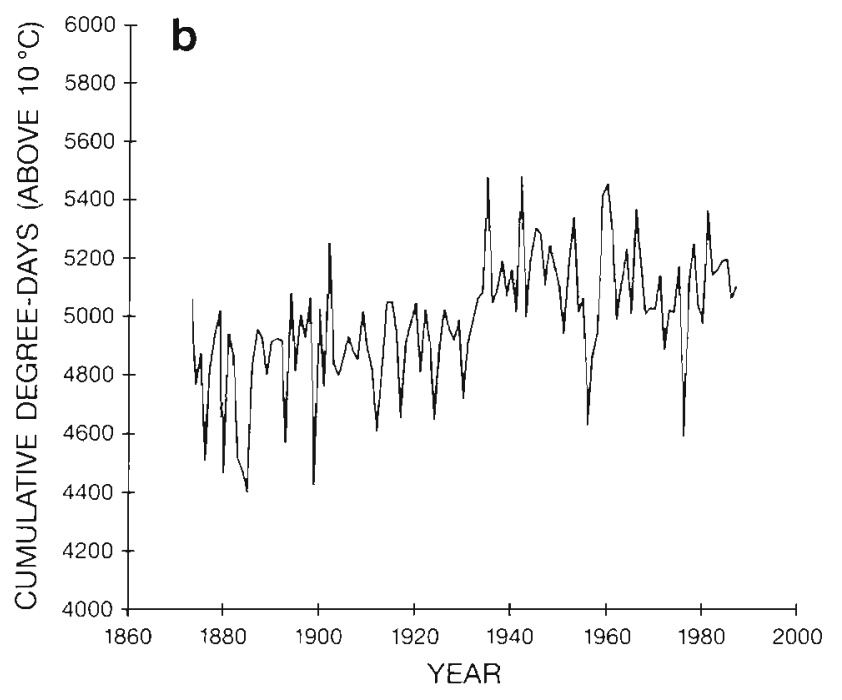

Yangtze River Delta. This quasi-stationary front is a result of the interaction between the southward and southeastward intrusion of the East Asian polar fronts and the seasonal northward progression of the summer monsoon (Chen \& Chang 1980). This front is usually found at the northern periphery of the tropical high (Zhang \& Crowley 1989) and moves from southwest to northeast, extending from southern China to Japan as the summer monsoon progresses. The front arrives in the Yangtze River Valley in May, June and early July, with a weak temperature gradient but a high moisture gradient (Lau \& Li 1984). The strength of this front and its arrival time at the Delta were found to be associated with ENSO activities. As a result of the front's high moisture content, large amounts of rainfall (as much as several hundred millimeters per day) fall during this period. The rainy spells can last from several days to weeks in the region. The June 1991 flood of the
Yangtze River Valley was associated with the Mei-Yu Front; this front arrived early and lingered for more than 8 wk in the Yangtze River Delta, causing the inundation of large areas in the Delta.

Climate variability, sea surface temperature and ENSO

Large interannual variability in precipitation in the Yangtze River Delta was found to be associated with ENSO events and sea surface temperature (SST) anomalies. The heavy precipitation resulting in regional floods during the Mei-Yu period in the Delta over the last $100 \mathrm{yr}$ are found to appear 6 to 7 mo after ENSO activities (Table 2). These floods were a result of an extended Mei-Yu period with heavy precipitation $\left(>100 \mathrm{~mm} \mathrm{~d}^{-1}\right.$ ). An extended Mei-Yu period after ENSO events often arrives 2 to $3 \mathrm{wk}$ earlier in the Delta and departs 2 to 3 wk later than a normal period.

The deviation from normal monthly rainfall over large areas of the middle and lower Yangtze River basin is correlated with the preceding winter's SST anomalies over the Kuroshio Current (Lau \& Li 1984). Large, well-developed, positive SST anomalies in the region of the Kuroshio Current during the preceding winter were reported to have led to the monsoon floods during the Mei-Yu periods of 1954 and 1983, which caused major disasters in central China and the Delta (Lau \& Li 1984). The elevated SSTs extended from $120^{\circ} \mathrm{E}$ to $95^{\circ} \mathrm{W}$ in the $1982 / 1983 \mathrm{ENSO}$. Following this, abnormally heavy precipitation occurred in the Yangtze River Valley and Delta during the Mei-Yu period in from May to July of 1983. Chen et al. (1990) noted that the amount of Mei-Yu rainfall is positively correlated to the SST of the Eastern Equatorial Pacific 
(EEP) $\left(160^{\circ} \mathrm{W}\right.$ to $100^{\circ} \mathrm{W}$ and $5^{\circ} \mathrm{S}$ to $\left.5^{\circ} \mathrm{N}\right)$ in the preceding 6 mo; warmer SSTs over the EEP are more likely to cause heavy rainfall in the Yangtze River Delta. During ENSO events, the heavy rains in the Delta were shown to be associated with a shift in the position of the Subtropical High of the Northwest Pacific and elevated SSTs (Zhang et al. 1987). The pressure difference between the Subtropical High and the Subtropical Low also increased during the summer after ENSO activities. The pressure differences between $100^{\circ} \mathrm{E}$ and $130^{\circ} \mathrm{E}$, and between $20^{\circ} \mathrm{N}$ and $30^{\circ} \mathrm{N}$, were larger during 1931 and 1954 than during the years without ENSO activities, and the trough in the subtropical low was much lower than in an average year. The occurrence of regional floods in this area appears to relate to spatial and/or temporal shifts of the mean climatological circulation and rainfall and is associated with anomalous boundary conditions of SST.

In July 1991, heavy precipitation and an extended Mei-Yu period again resulted in a regional flood which swept through 3 coastal provinces (Jiangsu, Zhejiang, and Anhui) in the Yangtze River Valley and Delta. An elevated SST $\left(>1^{\circ} \mathrm{C}\right)$ was noted in the EEP and Kuroshio Current regions during December 1990 and June and July 1991 (Kousky et al. 1991). Thus, the association of elevated SSTs and heavy rainfall in the Delta was again noted.

Variations in monsoon intensity affect the distribution of precipitation in eastern China. When the summer monsoon is strong, there is heavy precipitation in the North China Plain, and southern China and the Yangtze River Valley and Delta suffer from drought; when the summer monsoon is weak, however, heavy rainfall occurs in the Yangtze River Valley and Delta, and drought develops in the North China Plain and southern China (Guo 1987). The position and pressure of the Subtropical High can significantly influence the monsoon strength and regional climate in China. When the Subtropical High develops too strongly, the Yangtze River Valley and Delta suffer from drought.

\section{Predictability of extreme flood events}

Substantial climate variability following ENSO events has been a major phenomenon in this part of China. This study found that there were significant rainfall cycles of $2-3,5-6$ and 38 yr during the last $100 \mathrm{yr}$, but the intervals between flood events were 10 , 16,23 , and $29 \mathrm{yr}$. We note that all major floods in the Delta occurred after ENSO events, but not all ENSO activities led to major floods. Furthermore, we notice that the $\mathrm{QBO}$ shows a strong correlation with the weather pattern in this region, which is closely associated with the EAI. This is an indication that a 2-3 yr cycle can be a major contributor to the extreme flood events in the Delta. If we assume that the events of these extreme climate periods are a combination of the ENSO activities(5-6 yr cycle) and the QBO (2-3 yr), the hypothetical periods for extreme climate events would be $10,12,15$, and $18 \mathrm{yr}$. The actual intervals observed for extreme events correspond either to these hypothetical periods or to a combination of these periods: for example, 29 yr can be $10+18$ yr (with 1 yr variability), and 23 yr can be $10+12$ yr ( 1 yr variability). This suggests that the major flood events in the region are strongly influenced by ENSO activities and the $\mathrm{QBO}$ and that the periods with ENSO activities and a QBO rainfall maximum can be used to predict when flood events are likely to occur in the Delta.

\section{Effects of climate variability}

Large-scale demographic changes, increased agricultural and industrial development and expanded urbanization have greatly increased the impact of extreme climate events on the Delta region. The population of the Yangtze River Delta has shown a 4 -fold increase during this century alone. Increases in both population growth rate and redistribution rate are the key factors causing this change (Chang 1990, 1993b). In order to provide food for this ever-increasing population, large areas of wetlands and the flood drainage plains have been converted to rice paddies and fish ponds. Major increases in the amount of industry, especially rural industry, have become evident in townships across the Delta over the last 10 yr ('rural industry' is the term used for a class of small satellite industries which operate primarily in rural China). While these rural industries can rapidly adapt to market changes, they use outdated and inefficient technology, generating large amounts of waste materials, many of which are toxic. The annual rate of industrial growth in Suzhou City District (a major district in the Delta) averages $30 \%$. In addition to this high rate of growth, rapid urbanization of townships (small cities with populations of less than 3000) has taken place in the wetland area of the Delta. An estimated 4 -fold increase in the number of townships has been reported in the last $10 y r$.

High rates of siltation are found in rivers and lakes in the Delta (Chang 1993b). The silt reduces the capacity of the lakes to contain flood water during storms, and slows the drainage of flood water by the rivers. The heavy rain during the Mei-Yu period in 1991 is a case in point. The flood inundated a large part of the central lowland Delta for months as a result of poor river drainage due to siltation. The problem of accelerated siltation has not only reduced lake flood control capacity, but also led to the disappearance of many lakes. 
Many small lakes in the central Delta have been converted to fields, and the rate of lake disappearance in the Delta is so high that it has become a serious concern in terms of management of Chinese lakes (Chang 1987, 1990, 1993a, b). The disappearance of lakes further exacerbates the problem of flooding during the extreme rain events. Extensive human habitation in wetlands has further limited the use of the area for draining excess waters and thereby increased the severity of the floods.

Health risks also increase as the population density increases in the lowland areas of the Delta, and as more toxic industrial wastes are deposited and accumulated in the flood plain. When industries dispose of large quantities of wastes, including toxic materials, these are deposited in the wetland or lowland sediment, and often resurface as a result of inundation.

Major flood events have occurred frequently after ENSO activities in the Yangtze River Delta. Heavy precipitation ( $>100 \mathrm{~mm} \mathrm{~d}^{-1}$ ) and an extended rainy spell lasting from several weeks to months are the characteristics of these extreme climate events during the Mei-Yu period. These floods have severely impacted the lowland area of the Delta, and will recur when the climate conditions again become conducive to this. Casualties are often high in such floods. Recent changes in demographics, land use and rapid urbanization will only increase the impact of excessive rainfall, since the river drainage capacity and the lake storage capacity have been greatly reduced. The loss of wetlands reduces the area available to catch flood water inundation, while natural climate cycles are sure to continue. Integrated land and water management is badly needed in this part of Asia. This management should take into consideration major weather periods, major patterns of climate variability and recent changes due to human activities. Unless these trends are carefully monitored and considered, the effects of climate on man-made systems will increasingly be felt by society. Damage and casualties will rise as the systems developed and modified by man become less able to accommodate extreme climate events.

Acknowledgements. This publication is a result of work sponsored by the U.S. EPA Global Change Program of the Corvallis Environmental Research Laboratory, under cooperative agreement CR-817589. The authors thank Dr C. M. Liu for his assistance in statistical analyses and are grateful for helpful comments from 2 anonymous reviewers. We also thank the Chinese Academy of Meteorological Sciences for providing the weather data used in this study. The information in this article has been funded by the U.S. Environmental Protection Agency. It has been subjected to the Agency's peer and administrative review, and it has been approved for publication as an EPA document. Mention of trade names or commercial products does not constitute endorsement or recommendation for use.

\section{LITERATURE CITED}

Berlage, H. P. (1966). The Southern Oscillation and world weather. K. Ned. Meteorol. Inst. Meded. Verh. 88: $1-152$

Chang, W. Y. B. (1987). Large lakes of China. J. Great Lakes Res. 13(3): 235-249

Chang, W. Y. B. (1990). Human population, modernization and the changing face of China's eastern Pacific lowlands. China Exchange News 18(4): 3-8

Chang, W. Y. B. (1993a). Management of shallow tropical lakes using integrated lake farming: a review. In: Dudgeon, D., Lam, P. K. S. (eds.) Inland waters of tropical Asia and Australia: conservation and management. Mitt. int Verein. Limnol. 24: 219-224

Chang, W. Y. B. (1993b). Lake management in China. J. Asian environ. Mgmt 1(2): 15-31

Chen, D., Chen, L., Shen, R. (1991). Features of quasi3.5 year oscillation of zonal wind in troposhere. Q. J. appl. Meteorol. V2(1): 40-51

Chen, G. C. (1986). Droughts and floods in the Yangtze River Delta and related changes in the aquatic environments. Nanjing Institute of Geography, Nanjing

Chen, G. T. J., Chang, C.-P. (1980). The structure and vorticity budget of an early summer monsoon trough (Mei-Yu) over southeastern China and Japan. Mon. Weather Rev 108: 942-953

Chen, L., Chen, D., Shen, R., Zhang, Q. (1990). The interannual oscillation of rainfall over China and its relation to the interannual oscillation of the air-sea system. Acta Meteorologica Sinica 4(5): 598-611

Diaz, H. F., Fu, C. (1987). Regional precipitation and temperature variability and its relationship to the southern oscillation. In: Ye, D., Fu, C., Chao, I., Yoshino, M. (eds.) The climate of China and global climate. Springer-Verlag, Berlin, p. 249-255

Fairbridge, R. W. (1987). Bruckner cycle. In: Oliver, J. E., Fairbridge, R. W. (eds.) Encyclopedia of climatology. Van Nostrand Reinhold, New York, p. 184

Guo, Q. (1987). The East Asia Monsoon and the southern oscillation, 1871-1980. In: Ye, D., Fu, C., Chao, I., Yoshino, M. (eds.) The climate of China and global climate. Springer-Verlag, Berlin, p. 249-255

Hayden, B. P. (1993). LTER EI Niño Workshop: an El Niño primer. (Unpublished.) Department of Environmental Science, University of Virginia, Charlottesville

Kousky, V. E., Bell, G. D., Kopman, J. D. (1991). Climate diagnostics bulletin. National Meteorological Center, National Weather Service, NOAA, Silver Spring, MD

Lau, K.-M., Li, M.-T. (1984). The monsoon of East Asia and its global associations - a survey. Bull. Am. meteorol. Soc. 65: $114-125$

Lough, J. M., Fritts, H. C., Wu, X. (1987). Relationship between the climates of China and North America over the past four centuries: a comparison of proxy records. In: Ye, D., Fu, C., Chao, I., Yoshino, M. (eds.) The climate of China and global climate. Springer-Verlag, Berlin, p. $89-105$

Quinn, W. H., Neal, V. T., De Mayolo, S. E. A. (1987). El Niño occurrences over the past four and a half centuries. J. geophys. Res. 93(13): 13449-14461

Rasmusson, E. M., Arkin, P. A. (1987). El Niño/Southern Oscillation and the Asian monsoons. In: Ye, D., Fu, C., Chao, I., Yoshino, M. (eds.) The climate of China and global climate. Springer-Verlag, Berlin, p. 141-153

Rasmusson, E. M., Carpenter, T H. (1983). The relationship between eastern equatorial Pacific sea surface tempera- 
tures and rainfall over India and Sri Lanka. Mon. Weather Rev. 111: $517-528$

Redmond, K., Koch, R. W. (1991). Surface climate and streamflow variability in the western United States and their relationship to large-scale circulation indices. Water Resour. Res. 27(9): 2383-2399

SYSTAT (1990). The system for statistics. SYSTAT, Inc. Evanston, IL

Wang, S.-W., Zhao, Z.-C. (1981). Droughts and floods in China, 1470-1979. In: Wigley, T M. L., Ingrasham, M. J., Farmer, G. (eds.) Climate and history. Cambridge University Press, Cambridge, p. 271-288

Wei, W. W. S. (1990). Time series analysis: univariate

Editor: V. Meentemeyer, Athens, Georgia, USA and multivariate methods. Addison-Wesley, Inc., Los Angeles

Zhang, J., Crowley, T (1989). Historical climate records in China and reconstruction of past climates. J. Clim. 2(8): $833-849$

Zhang, Y., Li, Y., Bi, M. (1987). Abnormal heavy rainfall in the Changjiang valley and the correlation with extraordinary oceanic features in 1983. In: Ye, D., Fu, C., Chao, I., Yoshino, M. (eds.) The climate of China and global climate. Springer-Verlag, Berlin, p. 236

Zhu, R., Fu, C., Wang, Y (1990) Climate (abridged), No. 5. Blue Book of Science and Technology of China. China Meteorological Press, Beijing

Manuscript first received: December 21, 1993

Revised version accepted: March 7, 1994 